\title{
Guest Editorial: A Call for Contextualized Bioethics: Health, Biomedical Research, and Security
}

\author{
MARGIT SUTROP and KADRI SIMM
}

A decade has passed since the mapping of the human genome-an event that paved the way for many new developments in biomedicine and related fields. In ethics, this milestone was accompanied by calls for changes in ruling ethical frameworks. ${ }^{1}$ It was envisioned that concepts of solidarity, community, and public interest ought to play a more prominent role alongside traditional concepts of medical ethics such as autonomy, privacy, and informed consent. The rationale has been that new developments in biological sciences and information technologies have resulted in applications that seriously challenge the usefulness and even appropriateness of these basic traditional concepts. For example, many have argued that the concept of informed consent should either be modified (to open consent, broad consent, etc.) or, in some areas of application, abandoned altogether. Traditional informed consent ${ }^{2}$ has been criticized as too individual-centered (to the detriment of collective or community interests) and too formal and unnecessarily cumbersome to obtain. It has been suggested that a communitarian turn in medical ethics would solve some of the dilemmas introduced by new technologies. ${ }^{3}$

However, there are also plenty of bioethicists who continue to support rightsbased ethics as most appropriate in protecting research subjects from potential harm. These critics agree that there is a problem with too narrow an understanding of autonomy and too formalistic an application of informed consent; they point to the need to improve the process of obtaining informed consent, indeed, to reconceptualize informed consent altogether and reinterpret its underlying principle of respect for autonomy.

The aim of this special section is, first, to understand why the pendulum has swung from the requirement of fully informed consent (codified after World War II) to broad and open consent (in research related to biobanks) and even further to giving up consent (in the contexts of public health and security). We seek to discuss the ramifications of this move in terms of risks and benefits. Second, we wanted to relate these developments to changes in ethical

\footnotetext{
The articles published in this special section were first presented at a conference titled From Informed Consent to No Consent: The Challenges of New Ethical Frameworks, held on November 6-7, 2010, in Tartu, Estonia. The conference was organized with the help of the Estonian Science Foundation grant New Ethical Frameworks for Genetic and Electronic Health Record Databases, funded under EEA/ Norwegian financial mechanisms from 2008 to 2010. We gratefully acknowledge their support. Also, we would like to thank Kristi Lõuk for her assistance in conceptualizing the conference program and this special issue, Tiina Kirss for help with our English, and Laura Lilles for technical assistance with the articles. Last but not least, we would like to thank the editor Tomi Kushner for her enthusiasm and encouragement.
} 
frameworks and to understand the philosophical, ideological, and perhaps even political underpinnings of these processes.

We were likewise interested in the question of why ethical frameworks are changing. Is this rethinking a reaction to changes in scientific practice or a response to specific sociohistorical events and/or changing sociopolitical contexts? One can outline several reasons why bioethics since World War II has developed mainly in the liberal framework and why autonomy has become the foremost principle of bioethics. Clearly this shift toward an autonomy model is a reaction to the oppressive history of eugenics and coercion of human subjects in the name of so-called public interest.

The more recent, so-called communitarian turn is clearly related to the completion of the Human Genome Project. Parallel developments in biological sciences and information technologies have resulted in applications that seem to challenge governing ethical frameworks. Genetics has demonstrated our profound connectedness to our siblings, parents, other humans, and even animals, raising questions about the very possibility of drawing a line between what is mine and what belongs to others. This connectedness points to the relevance of values like solidarity, responsibility, and global justice in genetic research. At the same time, it also calls for the protection of communities, not just individuals, especially as genetic research can pose communal risks of stigmatization and discrimination.

In the public health arena, pressures on the individual autonomy model are also growing. More and more frequently, medical ethics is called on to resolve situations in which the health concerns of the individual collide with the interests of society as a whole (safety, economization of resources, etc.). It is stressed that public health measures must be compulsory if they are to be effective. ${ }^{4}$ Although the question of how to reconcile the interests of the individual with the interests of society has been relevant for a long time, it is now applied with even greater urgency in new disciplines and fields.

How successful has the so-called communitarian turn in bioethics been, both in theoretical debates and in the more applied fields of regulation? In view of the many recent studies on the concepts of autonomy and informed consent, ${ }^{5}$ it seems that calls for an alternative communitarian ideology have mobilized representatives of liberal individualism. Their goal is to show that we should be careful not to restrict or abandon the principle of autonomy in favor of other ethical principles, such as beneficence or public interest. Many seem to believe that the individual rights-centered ethical framework should be not replaced, but rather complemented by one in which more collective values are represented. This is the suggestion of neocommunitarian critics, who try to balance individual rights with community interests. Surely traditional concepts like autonomy, consent, and privacy have not lost their relevance. However, can we realistically hope to accommodate the values of both liberal individualism and communitarianism? How should the complex notion of public interest be construed and protected, and what are the conditions under which public interest may override individual interests? How shall we assess current developments in biometrics and other new technologies, in which security and solidarity seem to prevail over privacy and autonomy? What are the potential difficulties that accompany the employment of these new concepts for novel sociotechnical purposes such as digitalized health records and biobanks? 


\section{Guest Editorial}

The strength of our special section is that it compares a range of different contexts, spanning health, biomedical research, and security. It likewise takes into account historical changes in the conceptualization of bioethics from the 1970s until today. This is why this collection brings together leading figures of individual liberal ethics, prominent spokespeople for the communitarian turn in bioethics, as well as other leading bioethicists who provide a thorough philosophical analysis of the concepts of autonomy, consent, justice, solidarity, the common good, and the contested relationship of private and public interest.

All of the authors of this special issue are united by the understanding that we need to regard values from a pluralistic point of view, that there are no absolute values, only objective values, the prioritization of which depends on the context. The differences emerge in how this context is assessed, and how the values are then understood and interpreted, rather than in any a priori designation of a single prime value. The contexts themselves can be widely diverse-clinical medical research can differ significantly from research on genetic databases or public health context. Ethical frameworks must likewise reckon with a variety of sociopolitical contexts.

Thus this special section is a call for contextualized bioethics. In view of ongoing developments in science, medicine, and collateral fields, and historical shifts in society, the articles call attention to the need for ethical frameworks to be resonant and responsive to the contexts in which they are embedded. At the same time, we must be vigilant and sensitive about potential new threats. As the advancements in science and medicine have brought to the forefront arguments about the common good and public interest, there is also increased risk that these labels can be employed to further particular interests in the guise of common ones. ${ }^{6}$ Therefore, we should not turn the clock back and open the door for paternalism, thus promoting authoritarian or totalitarian tendencies in bioethics.

\section{Notes}

1. Callahan D. Bioethics: Private choice and common good. Hastings Centre Report 1994;24(3):28-31; Callahan D. Individual good and common good: A communitarian approach to bioethics. Perspectives in Biology and Medicine 2003;46(4):496-507.

2. The best overview of the introduction of the principle of informed consent is provided in Faden $\mathrm{R}$, Beauchamp T. A History and Theory of Informed Consent. Oxford: Oxford University Press; 1986.

3. Chadwick R, Berg K. Solidarity and equity: New ethical frameworks for genetic databases. Nature Reviews Genetics 2001;2:318-21; Knoppers BM, Chadwick R. The Human Genome Project: Under an international ethical microscope. Science 1994;265:2035-6; Knoppers BM, Chadwick R. Human genetic research: Emerging trends in ethics. Nature Reviews Genetics 2005;6:75-9; Lunshof JE, Chadwick R, Vorhaus DB, Church GM. From genetic privacy to open consent. Nature Reviews Genetics 2008;9:406-11.

4. O'Neill O. Public health or clinical ethics: Thinking beyond borders. Ethics and International Affairs 2004;16(2):35-45.

5. Beyleveld D, Brownsword R. Consent in the Law. Oxford: Hart; 2007; Kristinsson K. The Belmont Report's misleading conception of autonomy. Virtual Mentor. American Medical Association Journal of Ethics 2009;11:611-6; Kristinsson K. Autonomy and informed consent: A mistaken association? Medicine, Health Care and Philosophy 2007;10:253-64; O'Neill O. Autonomy and Trust in Bioethics. Cambridge: Cambridge University Press, 2002; Manson NC, O’Neill O. Rethinking Informed Consent in Bioethics. Cambridge: Cambridge University Press, 2007; Walker RL. Medical ethics needs a new view of autonomy. Journal of Medicine and Philosophy 2009;33:594-609.

6. Ashcroft RE. From public interest to political justice. Cambridge Quarterly of Healthcare Ethics 2004;13:20; Sutrop M, Simm K. Public and private interests in the genomic era: A pluralist approach. In: Gunning J, Holm S, eds. Ethics, Law and Society. Aldershot: Ashgate; 2008:205-16. 